\title{
Intestinal Growth and Development of Weanling Pigs in Response to Dietary Supplementation of Antibiotics, Phytogenic Products and Brewer's Yeast plus Bacillus Spores
}

\author{
C. Young Lee ${ }^{1}$, Jung-Won Lim ${ }^{1}$, Young-Hyun Ko ${ }^{1}$, Sun-Young Kang ${ }^{1}$, Man Jong Park ${ }^{1}$, Taegu Ko ${ }^{2}$, Ji Hoon Lee ${ }^{2}$, Young Hyun ${ }^{2}$, \\ Kyu-Sik Jeong ${ }^{3}$ and In Surk Jang ${ }^{1 *}$ \\ ${ }^{1}$ Regional Animal Industry Center, Gyeongnam National University of Science and Technology, Jinju 660-758, Korea, ${ }^{2}$ Bio \\ Resource Institute, 254-6 YangDae-Ri, Ipjang-Myun, ChunAn-City, Choongnam-Do 330-822, Korea, ${ }^{3}$ Department of \\ Pathology, College of Veterinary Medicine, Kyungpook National University, Daegu 702-701, Korea
}

\begin{abstract}
A total of 96 crossbred weanling barrows aged 21 days were randomly allocated to 32 pens of a new nursery to investigate the effects of antibiotics, phytogenics, and probiotics on intestinal growth and development. The animals were fed a set of three-phase basal diets containing $0.3 \%$ zinc oxide $(\mathrm{CON})$ or the basal diets supplemented with 353 ppm of a combination of tiamulin, neomycin, chlortetracycline, and oxytetracycline (ANTI), $75 \mathrm{ppm}$ triterpenoid saponin plus 150 ppm mixed saccharides (HERB; Sacchapin $^{\circledR}$ ), or $1 \times 10^{7}$ brewer's yeasts plus $8 \times 10^{7}$ spores of each of Bacillus licheniformis and Bacillus subtilis per kilogram feed (PROBIO; Yeasture Plus $2 \mathrm{~B}^{\circledR}$ ) for five weeks. Thirty-two pigs representing as many pens were slaughtered at the end of the feeding trial, after which morphological measures and digestive enzyme activities of intestinal mucosa were determined. Weight gain and gain:feed of the pigs were not affected by the dietary treatments (TRT) during the overall feeding trial. Total intestinal length was greater in PROBIO than in ANTI $(\mathrm{P}<0.05)$. Wet mucosa weight of the duodenum was not affected by TRT. However, jejunal mucosa weight was greater in PROBIO than in any other group sum of mucosa weights of the duodenum and jejunum was greater $(\mathrm{P}<0.05)$ in PROBIO than in ANTI and HERB. The height and width of duodenal villus were not affected by TRT, but crypt depth decreased $(\mathrm{P}<0.05)$ in response to HERB and PROBIO vs CON. Specific activities of alkaline phosphatase, sucrase, maltase, lactase, and leucine aminopeptidase in the duodenum and jejunum were not changed by TRT. In conclusion, results suggest that the present dietary treatments have no effects on growth performance of weanling pigs and that of PROBIO enhances intestinal growth and development under a clean experimental setting.
\end{abstract}

(Key words : Weanling pig, Antibiotic, Herb extract, Probiotic, Intestine)

\section{INTRODUCTION}

A variety of antibiotics and antimicrobial substances have been used as feed additives for the past several decades to improve the growth efficiency of post-weaning pigs (Visek, 1978; Cromwell, 2001). The enhanced growth efficiency of young pigs by these agents is elicited by virtue of their effective suppression of colonization of harmful microflora and ensuing altered gut function. The use of antibiotics as feed additives, however, has been prohibited since 2006 in EU because of the possible development of antibiotic resistance in humans as well as animals through such a practice (Snary et al., 2004; Phillips, 2007). Similarly, the number of antibiotics allowed as feed additives in Korea has been reduced from 53 to 25 followed by 18 and eventually zero as of July 1, 2011 (MIFAFF, 2004, 2010). It is thus imperative in Korea to find effective "alternatives to antibiotics," which include phytogenic substances, probiotics, prebiotics, acidifiers, etc. (Wenk, 2000; Windisch et al., 2008).

Plant extracts containing saponins, essential oils, flavonoids, organic acids, saccharides, etc., or mixtures of them have recently been introduced as feed additives (Cowan, 1999 Francis et al., 2002; Windisch et al., 2008). Of these, saponins extracted from a variety of plants represented by Yucca schidigera have been found to decrease intestinal ammonia production (Francis et al., 2002), to alleviate the oxidative stress (Olas etal., 2003), and to potentiate the immunomodulatory function (Ilsley et al., 2005; Kang et al.,

* Corresponding author: In Surk Jang, Regional Animal Industry Center, Gyeongnam National University of Science and Technology, Jinju 660-758, Korea. Tel: 055-751-3236, Fax: 055-751-3267, E-mail: isjang@gntech.ac.kr 
2010) by yet-to-be-understood mechanisms. However, phytogenics containing a specific type of saponin or essential oil rarely influence growth performance or intestinal mass in young pigs (Yen and Pond, 1993; Colina et al., 2001), whereas some mixtures of flavonoids, organic acids and polysaccharides have been reported to exhibit growth-promoting effects (Stein and Kil, 2006; Kong et al., 2007; Windisch et al., 2008; Yin et al., 2008).

Probiotics or direct-fed microbials have been used as dietary supplements for several decades (Cromwell, 2001; Lallès et al., 2007; Ohashi and Ushida, 2009). These agents are believed to colonize dominantly in the lower intestine where they inhibit the growth of enterotoxigenic microflora, Escherichia coli in particular, to elicit a beneficial effect on gut health, although their effects on growth performance have been either positive or insignificant. Of late, orally administered spores of Bacillus licheniformis and Bacillus subtilis have been reported to germinate in the gastrointestinal tract (Leser et al., 2008) and thereby to prevent post-weaning diarrhea and also to improve the production efficiency of growing-finishing pigs (Alexopoulos et al., 2004; Davis et al., 2008).

As an initial step to find effective alternatives to antibiotics, the present study was undertaken to investigate the effects of commercial phytogenic and probiotic products on growth performance and intestinal growth and development of weanling pigs and thereby to find insight into mechanisms of their actions. To this end, effects of the commercial products added to the diet were compared with those of dietary addition of none or a mixture of antibiotics.

\section{MATERIALS AND METHODS}

\section{Animals and experimental design}

A total of 96 crossbred, castrated weanling pigs aged 21 days and weighing $5.75 \pm 0.10 \mathrm{~kg}$ were randomly allocated to 32 pens of a new plastic slat-type nursery in such a way that each of the four dietary treatments (Table 1) was assigned eight $0.75-\mathrm{m}^{2}$ pens. The animals were adjusted for two days to the new environment including the phase 1 basal diet $(\mathrm{CON})$ or the basal diet supplemented with a combination of antibiotics (ANTI), phytogenic extracts (HERB), or probiotics (PROBIO).

The ANTI, which was a mixture of tiamulin, neomycin, chlortetracycline, and oxytetracycline, was formulated to
Table 1. Compositions of the experimental diets (as-fed basis)

\begin{tabular}{|c|c|c|c|}
\hline Item & Phase $1^{\mathrm{a}}$ & Phase $2^{\mathrm{b}}$ & Phase $3^{\mathrm{c}}$ \\
\hline \multicolumn{4}{|l|}{ Ingredients, $\%$} \\
\hline Treatment premix ${ }^{d}$ & 0.35 & 0.35 & 0.35 \\
\hline Corn & 30.87 & 38.69 & 58.32 \\
\hline Soybean meal-44 & 26.00 & 24.95 & 33.00 \\
\hline Fish meal & 5.00 & 5.00 & 3.00 \\
\hline Spray-dried porcine plasma & 2.00 & - & - \\
\hline Whey & 20.00 & 25.00 & - \\
\hline Lactose & 10.00 & - & - \\
\hline Soybean oil & 4.00 & 4.00 & 3.50 \\
\hline Monocalcium phosphate & 0.25 & 0.35 & - \\
\hline Dicalcium phosphate & - & - & 0.35 \\
\hline Limestone & 0.55 & 0.70 & 0.77 \\
\hline Salt & 0.20 & 0.20 & 0.20 \\
\hline$L$-Lysine & 0.16 & 0.15 & - \\
\hline$D L$-Methionine & 0.12 & 0.11 & 0.01 \\
\hline Vitamin premix $^{\mathrm{e}}$ & 0.10 & 0.10 & 0.10 \\
\hline Mineral premix ${ }^{\mathrm{f}}$ & 0.10 & 0.10 & 0.10 \\
\hline $\mathrm{ZnO}$ & 0.30 & 0.30 & 0.30 \\
\hline Total & 100.00 & 100.00 & 100.00 \\
\hline \multicolumn{4}{|l|}{ Calculated chemical composition } \\
\hline Metabolizable energy, Mcal $/ \mathrm{kg}$ & 3.45 & 3.43 & 3.44 \\
\hline Crude protein, $\%$ & 21.04 & 20.49 & 20.74 \\
\hline Lysine, $\%$ & 1.50 & 1.40 & 1.24 \\
\hline Methionine, $\%$ & 0.45 & 0.43 & 0.38 \\
\hline $\mathrm{Ca}, \%$ & 0.75 & 0.75 & 0.64 \\
\hline $\mathrm{P}, \%$ & 0.66 & 0.67 & 0.56 \\
\hline
\end{tabular}

a,b,c Fed successively for 1, 2 and 2 weeks, respectively.

d Provided: none (referred to as $C O N$ in the text and all the other tables); 44 ppm tiamulin, 99 ppm neomycin, 110 ppm chlortetracycline, and 110 ppm oxytetracycline (ANTI); $75 \mathrm{ppm}$ triterpenoid saponin and $150 \mathrm{ppm}$ mixed saccharides (HERB; Sacchapin ${ }^{\circledR}$ extracted from the Yucca root and Camekkia Japonia $L$.); $1 \times 10^{7}$ brewer's yeasts plus $8 \times 10^{7}$ viable spores of each of Bacillus licheniformis and Bacillus subtilis (PROBIO; Yeasture Plus $\left.2 \mathrm{~B}^{\circledR}\right)$. The latter two are proprietary products of EasyBio System, Inc. (Seoul). Corn was used as the carrier of each premix.

e Provided per kg diet: 8,000 IU vitamin A, 2,500 IU vitamin $\mathrm{D}_{3}, 30 \mathrm{IU}$ vitamin E, $3 \mathrm{mg}$ vitamin $\mathrm{K}, 1.5 \mathrm{mg}$ thiamin, $10 \mathrm{mg}$ riboflavin, $2 \mathrm{mg}$ vitamin $\mathrm{B}_{6}, 40 \mu \mathrm{g}$ vitamin $\mathrm{B}_{12}, 30 \mathrm{mg}$ pantothenic acid, $60 \mathrm{mg}$ niacin, 0.1 $\mathrm{mg}$ biotin, and $0.5 \mathrm{mg}$ folic acid.

${ }^{\mathrm{f}}$ Providied per kg diet: $200 \mathrm{mg} \mathrm{Cu}, 100 \mathrm{mg} \mathrm{Fe}, 150 \mathrm{mg} \mathrm{Zn}, 60 \mathrm{mg} \mathrm{Mn}, 1$ $\mathrm{mg} \mathrm{I}, 0.5 \mathrm{mg} \mathrm{Co}$, and $0.3 \mathrm{mg}$ Se.

provide maximum doses of these wide-spectrum antibiotics formerly allowed by MIFAFF (2004; 353 ppm in total; see Table 1 legend for details) so as to maximally inhibit the 
growth of enteric gram-negative and -positive bacteria. The HERB (Sacchapin ${ }^{B}$ ), which was a blend of extracts of the Yucca root and Camekkia Japonica L., contained $150 \mathrm{ppm}$ triterpenoid saponin and $150 \mathrm{ppm}$ mixed saccharides; PROBIO (Yeasture Plus $2 \mathrm{~B}^{\circledR}$ ) was a mixture of the brewer's yeast and viable spores of Bacillus licheniformis and Bacillus subtilis these two proprietary products of EasyBio System, Inc. (Seoul), were added to the corresponding diets following the recommendations of the manufacturer.

Each group of animals had a free access to water and corresponding phase-1, -2 and -3 diets supplemented with identical agents for 1,2 and 2 weeks, respectively. Indoor temperature of the nursery was controlled at $30^{\circ} \mathrm{C}$ at the beginning of the feeding trial and was adjusted downward at a rate of $0.5^{\circ} \mathrm{C} /$ week. Feed intake was recorded at the end of weeks 1, 3 and 5; body weight was measured at the beginning and end of the feeding trial.

\section{Preparation of intestinal mucosa specimen and microscopic examination of villi}

At the end of the five-week feeding trial, 32 medianweight pigs representing as many pens were sacrificed using an electric stunner. Immediately after bleeding and opening the abdominal cavity, the entire small intestine was removed following excisions at the pylorus and at the iliocecal valve and the total intestinal length was measured. The intestine was perfused with $0.9 \%$ ice-cold saline, gently squeezed to remove the digesta, and divided into the duodenum and jejunum, which were defined as upper $10 \%$ and $50 \%$ lengths of the intestine, respectively.

As for five animals per treatment which were selected randomly at slaughter, a 5-cm cross-sectional segment of the duodenal length was cut at the midpoint and gently rinsed in ice-cold phosphate-buffered saline. This was further cut into a few shorter segments and fixed in a $10 \%$ formalin solution (Sigma Chemical Co., St. Louis, MO, USA). The fixed duodenal segment was subsequently embedded in paraffin wax, sliced longitudinally to a 4- $\mu \mathrm{m}$ thickness using a microtome and stained with hematoxylin and eosin. The height, width and crypt depth of the villus were measured under a microscopic field (BX-50, Olympus, Tokyo, Japan) using Visus image analysis program(Foresthill Products, Foresthill, CA, USA). Each of these variables was measured at 10 or more villi per animal and the average of the measurements was used as the observation for that pig.

\section{Harvesting the intestinal mucosa}

At the same time when the duodenal segment was taken for microscopic examination, the remaining or whole duodenum and the whole jejunum were rinsed three times with a Tris-buffered mannitol solution [mannitol buffer; 150 $\mathrm{mM}$ mannitol in $10 \mathrm{mM}$ Tris succinate $(\mathrm{pH}$ 7.4), $5 \mathrm{mM}$ $\mathrm{MgCl}_{2}, 5 \mathrm{mM} \mathrm{K} \mathrm{HPO}_{4}$ and $1 \mathrm{mM} \mathrm{MnCl}_{2}$. Mucosal tissue was harvested by gently scraping the internal surface of the intestinal segment with a glass slide on an ice-cold aluminum pan, after which residual fat and digesta remaining in the harvested mucosa were removed by suspending the tissue in an equal volume of the mannitol buffer followed by centrifugation at $10,000 \times \mathrm{g}$ at $4^{\circ} \mathrm{C}$ for $12 \mathrm{~min}$. After weighing the mucosal sediment, the mucosa was homogenized with six volumes of the mannitol buffer and aliquots of the resulting homogenate were stored at $-70^{\circ} \mathrm{C}$ until used for the enzyme assay.

\section{Determination of specific activities of digestive enzymes}

The frozen mucosal homogenate was thawed and diluted with an equal volume of $2 \%$ triton $\mathrm{X}-100$ to release brush-border enzymes from the membrane fraction. Protein content of the mucosal homogenate was determined by the bicinchronic acid (BCA) method using a BCA protein assay kit (Pierce, Rockford, IL, USA).

Alkaline phosphatase activity was measured using Sigma Diagnostic Assay Kit (Procedure No, 245) and an ELISA reader $\left(\mathrm{V}_{\max }\right.$ Molecular Device, Sunnywale, CA, USA) following the manufacturer's instruction. Leucine aminopeptidase activity was determined according to the procedure described by Rybina et al.(1997) in which the amount of $p$-nitroaniline produced from $L$-Leucine- $p$-nitroanilide by the catalysis of the enzyme is determined spectrophotometrically. Lactase, maltase and sucrase activities were determined by a procedure modified from that of Dahlqvist (1968); the end product glucose was determined using an ELISA reader with its wavelength set at $450 \mathrm{~nm}$. In all the assays described above, the unit activity and specific activity of each enzyme were defined as the yield of one micromole of end product and the rate of yield of the end product per minute by one milligram of protein, respectively.

\section{Statistical analysis}


All data were analyzed using GLM of SAS (SAS Institute Inc., Cary, NC, USA) to separate the means for the four dietary groups by Duncan's Multiple-Range Test, in which two groups were considered different if $\mathrm{P}<0.05$. The model included the dietary treatment, with the pen regarded as the experimental unit. In the analysis for the length and mucosa weight of the intestine, live weight was included in the model as a covariate.

\section{RESULTS}

\section{Growth performance}

All animals exhibited no apparent sign of health problem including diarrhea during the entire feeding trial. Growth performance of the piglets fed a set of basal diets (CON) or the basal diets supplemented with a combination of antibiotics (ANTI), a blend of phytogenic extracts (HERB), or a mixture of probiotics (PROBIO) are presented in Table 2. Overall ADG was not affected by the dietary treatments. The ADFI also did not differ between any two dietary groups during week 1 , weeks 2 and 3, weeks 4 and 5, or the entire 5-week period. As could be expected from these results, gain:feed was not influenced by the dietary treatment.

\section{Gross measures of the intestine and its mucosa}

Interestingly, total intestinal length was greater in the PROBIO group than in ANTI, but except for this, it did not differ between any other two groups (Table 3). The weight of duodenal mucosa was apparently lowest in the ANTI group, but the treatment effect was not different between any two groups due to relatively large variations among the pigs. Similarly, mucosal weights of the jejunum and duodenum plus jejunum also were apparently lowest in the ANTI group, although differences between the ANTI and any other group but PROBIO were not significant. Furthermore, the PROBIO group exhibited a greater jejunal mucosa weight than any other group $(\mathrm{P}<0.05)$ and also a greater duodenal plus jejunal mucosa weight than ANTI and HERB groups $(\mathrm{P}<0.05)$.

Table 2. Effects of the dietary treatment on growth performance of weaned barrows ${ }^{1)}$

\begin{tabular}{lcccc}
\hline Item & CON & ANTI & HERB & PROBIO \\
\hline \hline Initial wt, kg & $5.82 \pm 0.09$ & $5.76 \pm 0.14$ & $5.62 \pm 0.08$ & $5.62 \pm 0.10$ \\
Final wt, kg & $18.65 \pm 0.54$ & $18.58 \pm 0.35$ & $17.48 \pm 0.36$ & $17.43 \pm 0.42$ \\
ADG, g & $367 \pm 13.8$ & $366 \pm 11.5$ & $339 \pm 10.5$ & $337 \pm 12.0$ \\
ADFI, g & & & $460 \pm 3.1$ & $450 \pm 4.3$ \\
Wk 1 & $456 \pm 5.1$ & $455 \pm 3.8$ & $549 \pm 3.1$ & $552 \pm 1.5$ \\
Wk 2 and 3 & $561 \pm 3.0$ & $556 \pm 2.8$ & $889 \pm 4.4$ & $885 \pm 3.4$ \\
Wk 4 and 5 & $914 \pm 23.3$ & $895 \pm 3.6$ & $667 \pm 2.3$ & $665 \pm 2.4$ \\
Overall & $681 \pm 10.2$ & $672 \pm 2.0$ & $0.51 \pm 0.02$ & $0.51 \pm 0.02$ \\
Gain: feed & $0.54 \pm 0.02$ & $0.55 \pm 0.02$ & & \\
\hline
\end{tabular}

${ }^{1)}$ See the Table 1 legend for details of each dietary treatment. Data are means \pm SE of eight pens. None of the variable differed between any two groups $(\mathrm{P}>0.05)$.

Table 3. Effects of the dietary treatment on intestinal lengths and mucosa weights of weaned brrows ${ }^{1)}$

\begin{tabular}{lcccc}
\hline Item & CON & ANTI & HERB & PROBIO \\
\hline \hline Live weight, kg & $18.05 \pm 0.73$ & $18.13 \pm 0.41$ & $17.57 \pm 0.45$ & $17.68 \pm 0.55$ \\
Total intestinal length, cm & $1,228 \pm 51^{\mathrm{ab}}$ & $1,139 \pm 32^{\mathrm{a}}$ & $1,184 \pm 17^{\mathrm{ab}}$ & $1,265 \pm 47^{\mathrm{b}}$ \\
Duodenal (D) mucosa, g & $53.8 \pm 2.4$ & $40.9 \pm 4.1$ & $48.1 \pm 2.9$ & $47.9 \pm 3.6$ \\
Jejunal (J) mucosa, g & $188.4 \pm 6.8^{\mathrm{a}}$ & $176.2 \pm 10.1^{\mathrm{a}}$ & $184.3 \pm 7.8^{\mathrm{a}}$ & $213.6 \pm 8.1^{\mathrm{b}}$ \\
D + J mucosa, g & $242.2 \pm 7.7^{\mathrm{ab}}$ & $217.2 \pm 13.4^{\mathrm{a}}$ & $232.4 \pm 9.1^{\mathrm{a}}$ & $261.5 \pm 7.1^{\mathrm{b}}$ \\
\hline
\end{tabular}

\footnotetext{
${ }^{1)}$ See the Table 1 legend for details of each dietary treatment. Live weight was included in the model as a covariate in all the variables except for the live weight itself. Data are means \pm SE of eight pigs selected from as many pens.

${ }^{\mathrm{a}, \mathrm{b}, \mathrm{c}}$ Means with different superscripts within a row differ $(\mathrm{P}<0.05)$.
} 


\section{Morphology of the duodenal villi}

The height and width of the villus ( $\mathrm{VH}$ and $\mathrm{VW}$ ) did not differ between any two dietary groups (Fig. 1; Table 4). Crypt depth of the villus (CD), however, was reduced by HERB and PROBIO compared with that of $\mathrm{CON}(\mathrm{P}<0.05)$. Conversely, the mean VH:CD ratio was greater in PROBIO and HERB groups vs CON by $49 \%$ and $37 \%$, respectively, but differences between the former and the latter were not significant.

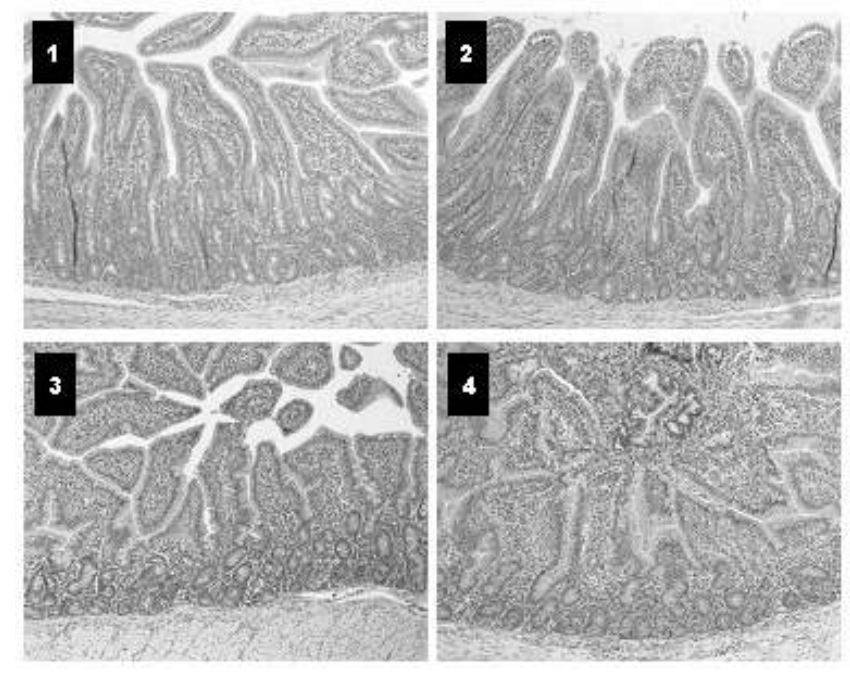

Fig. 1. Histomorphology of the duodenal villi of the piglets.

Post weaning piglets received one of the four dietary treatments, i.e. CONT, ANTI, HERB, and PROBIO, indicated as $1,2,3$, and 4, respectively, within the figure boxes. For details of the treatment, see the Table 1 legend. Representative results are shown here.

\section{Mucosal enzyme activities}

Specific activities of alkaline phosphatase, leucine amino peptidase, sucrase, lactase, and maltase in duodenal mucosa were numerically but not statistically greater in the ANTI than in any other group (Table 5). In jejunum, none of these enzyme activities changed in response to any of the dietary treatments.

\section{DISCUSSION}

Weaning influences intestinal structure and function adversely in the pig, usually resulting in diarrhea and growth retardation (Lallès, et al., 2007). It is well known that $0.15 \%$ to $0.3 \%$ in-feed supplementation of zinc oxide $(\mathrm{ZnO})$ often alleviates the post-weaning health problem to an extent comparable to that elicited by an in-feed antibiotic addition (Hill et al., 2001; Owusu-Asiedu et al., 2003), although such a high $\mathrm{ZnO}$ level can potentially result in soil contamination with excreted $\mathrm{Zn}$ through the manure. Nevertheless, since such a level of $\mathrm{ZnO}$ is indeed added to most commercial nursery pig diets in Korea, the present feeding trial was performed on basal diets containing $0.3 \% \mathrm{ZnO}$. As such, the possibility that effects of the agents on growth tested in the present study could have been masked by that of supplemental zinc oxide cannot be completely ruled out. However, there is an incident where a $0.31 \%$ dietary supplementation of $\mathrm{ZnO}$ exerted no effect on growth performance in weaned pigs (Broom et al., 2006) and further even the dietary antibiotic treatment, which is believed to have a growth promoting effect independently of that of $0.15 \%$ to $0.3 \% \mathrm{ZnO}$ (Hill et al., 2001), exerted no effect on growth.

The increase of jejunal mucosa weight in response to PROBIO vs CON suggests that like some other probiotics (Ohashi and Ushida, 2009), the brewer's yeast, Bacillus licheniformis and Bacillus subtilis, en masse, may also enhance epithelial cell growth in the gut. Moreover, mucosal weights of the jejunum and duodenum plus jejunum, as well as total intestinal length, were less in the ANTI than in PROBIO group, implicating that these two treatments have different mechanisms of regulatory actions on longitudinal

Table 4. Histomorphological measures of duodenal villi of the weaned barrows ${ }^{1)}$

\begin{tabular}{lrrrr}
\hline Item & \multicolumn{1}{c}{ CON } & \multicolumn{1}{c}{ ANTI } & HERB & PROBIO \\
\hline \hline Villus height $(\mathrm{VH}), \mu \mathrm{m}$ & $775.4 \pm 66.6$ & $802.4 \pm 59.3$ & $691.5 \pm 61.1$ & $731.3 \pm 54.8$ \\
Villus width $(\mathrm{VW}), \mu \mathrm{m}$ & $275.0 \pm 16.5$ & $229.5 \pm 14.7$ & $257.3 \pm 17.3$ & $247.3 \pm 17.9$ \\
Crypt depth $(\mathrm{CD}), \mu \mathrm{m}$ & $396.7 \pm 48.6^{\mathrm{a}}$ & $349.6 \pm 41.8^{\mathrm{ab}}$ & $254.8 \pm 35.7^{\mathrm{b}}$ & $258.8 \pm 42.9^{\mathrm{b}}$ \\
VH:CD ratio & $2.14 \pm 0.42$ & $2.58 \pm 0.62$ & $2.93 \pm 0.44$ & $3.19 \pm 0.57$ \\
\hline
\end{tabular}

\footnotetext{
${ }^{1)}$ See the Table 1 legend for details of each dietary treatment. Data are means $\pm \mathrm{SE}$ of five pigs selected from as many pens.

${ }^{\mathrm{a}, \mathrm{b}}$ Means with different superscripts within a row differ $(\mathrm{P}<0.05)$.
} 
Table 5. Digestive enzyme activities of the intestinal mucosa of the weaned barrows ${ }^{1)}$

\begin{tabular}{lcccc}
\hline Item & CON & ANTI & HERB & PROBIO \\
\hline \hline Duodenum & \multicolumn{5}{c}{$-\mu$ mol end product/mg protein/min - } \\
ALP $^{\mathrm{a}}$ & $6.00 \pm 0.57$ & $7.62 \pm 1.18$ & $6.18 \pm 0.84$ & $6.94 \pm 0.76$ \\
LAP $^{\mathrm{a}}$ & $2.71 \pm 0.25$ & $3.48 \pm 0.39$ & $3.10 \pm 0.28$ & $3.22 \pm 0.41$ \\
Sucrase & $1.17 \pm 0.08$ & $1.49 \pm 0.13$ & $1.42 \pm 0.10$ & $1.36 \pm 0.11$ \\
Lactase & $0.65 \pm 0.07$ & $0.77 \pm 0.13$ & $0.48 \pm 0.11$ & $0.50 \pm 0.07$ \\
Maltase & $8.70 \pm 0.77$ & $10.76 \pm 1.50$ & $7.95 \pm 0.59$ & $8.14 \pm 0.67$ \\
\hline Jejunum & & & \\
ALP & $6.03 \pm 0.95$ & $5.14 \pm 0.59$ & $5.15 \pm 0.61$ & $6.28 \pm 0.52$ \\
LAP & $2.70 \pm 0.19$ & $3.00 \pm 0.35$ & $3.01 \pm 0.33$ & $3.30 \pm 0.30$ \\
Sucrase & $1.68 \pm 0.20$ & $1.74 \pm 0.13$ & $1.52 \pm 0.10$ & $1.56 \pm 0.18$ \\
Lactase & $0.82 \pm 0.11$ & $0.86 \pm 0.15$ & $0.61 \pm 0.12$ & $0.70 \pm 0.08$ \\
Maltase & $9.21 \pm 1.22$ & $9.39 \pm 0.83$ & $8.52 \pm 0.99$ & $9.60 \pm 0.95$ \\
\hline
\end{tabular}

${ }^{1)}$ See the Table 1 legend for details of each dietary treatment. Data are means \pm SE of eight pigs selected from as many pens. None of the variables differed between any two groups.

${ }^{a}$ ALP, alkaline phosphatase; LAP, leucine aminopeptidase.

and mucosal growth of the intestine. In addition, compared with CON, the ANTI group exhibited lesser mucosal weights of the duodenum, jejunum and duodenum plus jejunum by $24.0 \%, 6.5 \%$ and $10.3 \%$, respectively, albeit statistically insignificant, which was similar to previous reports (Stutz et al., 1983; Fethiere and Miles, 1987; Veselinova et al., 1987). These results are thus thought to be reflective of the generally accepted concept that antibiotics dampen the mucosal thickening induced by enterotoxigenic microorganisms in the gut, which results in an increase of the proportion of absorbed nutrients utilized for growth of tissues other than the gut usually contributing to enhancement of growth performance (Visek, 1978; Cromwell, 2001).

The digestive capacity of weaned piglets is generally assessed based on the measurements of the villus height (VH) and crypt depth(CD) as well as digestive enzyme activities of intestinal mucosa. In this regard, the VH:CD ratio, which represents the absorptive area and hence absorptive capacity of the intestine, is probably a better indicator than either of the two independently (Manzanilla et al., 2006; Zhao et al., 2007). In general, weaned piglets have decreased digestive capacity as indicated by lesser $\mathrm{VH}$ and greater $\mathrm{CD}$ compared with those of age-matched sucklings (Kelly et al., 1991).

It was intriguing that HERB and PROBIO groups exhibited decreased $\mathrm{CD}$ compared with that of CON. Biological significance of this, however, remains to be known, because $\mathrm{VH}$ did not change in response to HERB or PROBIO and theeffects of these treatments on the $\mathrm{VH}: \mathrm{CD}$ ratio was insignificant. Of course, the present results obtained with HERB and PROBIO cannot be directly compared with published results, if any, either, not only because effects of these agents on intestinal villus morphology have not been studied, but because their effects are known to vary depending on the active principles contained in each product (Domeneghini et al., 2006; Windisch et al., 2008). For instance, Sehm et al. (2007) have reported that polyphenol (a flavonoid)-rich red-wine pomace and apple pomace alleviated the decrease of $\mathrm{VH}$ of weanling pigs, whereas in the study of Manzanilla et al. (2006), a mixture of plant extracts containing essential oils (carvacrol and cinnamaldehyde) and capsaicin did not influence $\mathrm{VH}$ or $\mathrm{CD}$. On the other hand, the absence of effects of ANTI on VH and CD, which was similar to the results obtained with avilamycin(van der Peet-Schwering et al., 2007) and amoxicillin (Thymann et al., 2007), suggests that the beneficial effect of antibiotics in weaned piglets is not likely to have any relation to their effects on the villus structure. In birds, conflicting results increased intestinal VH(Solomon and Tullett, 1988) and decreased VH and CD (Miles et al., 2006)-have been reported for the dietary antibiotic virginiamycin.

It also was noticeable that duodenal digestive enzyme activities were greater numerically, albeit not statistically, in the ANTI vs CON (25\% on an average) and other groups. This is thought to be consistent with the known fact that antibiotics, in general, enhance digestive capacity (Windisch et al., 2008) including stimulation of selective enzyme activities (Thymann et al., 2007) in young pigs. However, the 
lack of effect of PROBIO on the digestive enzyme activities was different from the increased activities of disaccharidases and oligo-peptidases in response to dietary probiotics containing a mixture of multiple strains of Lactobacillus plantarum, Lactobacillus acidophilus, Lactobacillus casei and Streptococcus faecium in the study of Collington et al. (1990). This implies that the effect of a probiotic product on the digestive enzyme activity is likely to be dependent on the species of the microorganisms or their spores contained in the product. To our knowledge, phytogenic products have not been studied in the pig with respect to their effect on the digestive enzyme activity, whereas in birds, a number of phytogenic essential oils have been reported to stimulate the secretion of digestive enzymes in the intestine(Lee, 2002; Jang et al., 2004, 2007).

In conclusion, results suggest that PROBIO enhances intestinal mucosal growth and that both PROBIO and HERB have a villus crypt-shortening effect. On the other hand, the lack of effects of the present dietary treatment including ANTI on growth performance is attributable to our clean experimental setting in which effects of the growth enhancers are known to be diminished (Visek, 1978; Cromwell, 2001). More studies are therefore necessary to delineate how the effects of these agents are related to digestive capacity of post-weaning pigs and also to elucidate how they are related to pig growth under production farm conditions and thereby to evaluate the practical efficacy of the products as alternatives to antibiotics.

\section{ACKNOWLEDGEMENTS}

This work was supported by Easybio System, Inc., and the Regional Animal Industry Center at Gyeongnam National University of Science and Technology.

\section{REFERENCES}

Alexopoulos, C., Georgoulaskis, I. E., Tzivara, A., Kyriakis, C. S., Govaris, A. and Kyriakis, S. C. 2004. Field evaluation of the effect of a probiotic-containing Bacillus licheniformis and Bacillus subtilis spores on the health status, performance, and carcass quality of grower and finisher pigs. J. Vet. Med. A. Physiol. Pathol. Clin. Med. 51:306-312.

Broom, L. J., Miller, H. M., Kerr, K. G. and Knapp, J. S. 2006. Effects of zinc oxide and Enterococcus faecium SF68 dietary supplementation on the performance, intestinal microbiota and immune status of weaned piglets. Res. Vet. Sci. 80:45-54.

Colina, J. J., Lewis, A. J., Miller, P. S. and Fischer, R. L. 2001. Dietary manipulation to reduce aerial ammonia concentrations in nursery pig facilities. J. Anim. Sci. 79:3096-3103.

Collington, G. K., Parker, D. S. and Armstrong, D. G. 1990. The influence of inclusion of either an antibiotic and a probiotic in the diet on the development of digestive enzyme activity in the pig. Br. J. Nutr. 64:59-70.

Cowan, M. M. 1999. Plant products as antimicrobial products. Clin. Microbiol. Rev. 12:564-582.

Cromwell, G. L. 2001. Antimicrobial and promicrobial agents. In: Lewis, A. J. and Southern, L. L. (Eds.), Swine Nutrition, second ed. CRC Press, Boca Raton, FL, USA, pp. 401-426.

Dahlqvist, A. 1968. Assay of the intestinal disaccharidase. 1968. Anal. Biochem. 22:99-107.

Davis, M. E., Parrott, T., Brown, D. C., de Rodas, B. Z., Johnson, Z. B, Maxwell, C. V. and Rehberger, T. 2008. Effect of a Bacillus-based direct-fed microbial feed supplement on growth performance and pen cleaning characteristics of growingfinishing pigs. J. Anim. Sci. 86:1459-1467.

Domeneghini, C., Di Giancamillo, A., Arrighi, S. and Bosi, G. 2006. Gut-trophic feed additives and their effects upon the gut structure and intestinal metabolism. State of the art in the pig, and perspectives towards humans. Histol. Histopathol. 21:273283.

Fethiere, R. and Miles, R. D. 1987. Intestinal tract weight of chicks fed an antibiotics and probiotics. Nutr. Rep. Int. 36: 1305-1309.

Francis, G., Kerem, Z., Makkar, H. P. S. and Becker, K. 2002. The biological action of saponins in animal systems: a review. Br. J. Nutr. 88:587-605.

Hill, G. M., Mahan, D. C., Carter S. D., Gromwell, G. L., Ewan, R. C., Harrold, R. L., Lewis, A. J., Miller, P. S., Shurson, G. C. and Veum, T. L. 2001. Effect of pharmacological concentrations of zinc oxide with or without the inclusion of an antibacterial agent on nursery pig performance. J. Anim. Sci. 79:934-941.

Ilsley, S. E., Millers, H. M. and Kamel, C. 2005. Effects of dietary quillaja saponin and curcumin on the performance and immune status of weaned piglets. J. Anim. Sci. 83:82-88.

Jang, I. S., Ko, Y. H., Kang, S. Y. and Lee, C. Y. 2007. Effect of a commercial essential oil on growth performance, digestive enzyme activity and intestinal microflora population in broiler chickens. Anim. Feed Sci. Technol. 134:304-315.

Jang, I. S., Ko, Y. H. Yang, H. Y. Ha, J. S., Kim, J. Y., Kim, J. Y., Kang, S. Y., Yoo, D. H. Nam, D. S., Kim, D. H. and 
Lee, C. Y. 2004. Influence of essential oil components on growth performance and the functional activity of the pancreas and small intestine in broiler chickens.Asian-Aust. J. Anim. Sci. 17:394-400.

Kang, P., Xiao, H. L., Hou, Y. Q., Ding, B. Y., Liu, Y. L., Zhu, H. L., Hu, Q. Z., Hu, Y. and Yin, Y. L. 2010. Effects of Astragalus polysaccharides, Achyranthes bidentata polysaccharides and Acantbepanax senticosus saponin on the performance and immunity in weaned pigs. Asian-Aust. J. Anim. Sci. 23, 750-756.

Kelly, D., Smyth, J. A. and McCracken, K. J. 1991. Digestive development of the early-weaned pig. 2. Effect of level of food intake on digestive enzyme activity during the immediate post-weaning period. Br. J. Nutr. 65:181-188.

Kong, X. F., Wu, G. Y., Liao, Y. P., Hou, Z. P., Liu, H. J., Yin, F. G., Li, T. J., Huang, R. L., Zhang, Y. M., Deng, D., Kang, P., Wang, R. X., Tang, Z. Y., Yang, C. B., Deng, Z. Y., Xiong, H., Chu, W. Y., Ruan, Z., Xie, M. Y. and Yin, Y. L. 2007. Effects of Chinese herbal ultra-fine powder as a dietary additive on growth performance, serum metabolites and intestinal health in early-weaned piglets. Livest. Sci. 108: 272-275.

Lallès, J. P., Bosi, P., Smidt, H. and Stokes, C. R. 2007. Nutritional management of gut health in pigs around weaning. Proc. Nutr. Soc. 66:260-268

Lee, K. W. 2002. Essential oils in Broiler Nutrition. Thesis. Department of Nutrition, Faculty of Veterinary Medicine, Utrecht University, Utrecht, the Netherlands.

Leser, T. D., Knarreborg, A. and Worm, J. 2008. Germination and outgrowth of Bacillus subtilis and Bacillus licheniformis spores in the gastrointestinal tract of pigs. J. Appl. Microbiol 104:1025-1033.

MIFAFF. 2004. Classification and Specification of Hazardous Feeds (published in Korean; translated into English). Notification No. 2004-72, Ministry for Food, Agriculture, Forestry and Fisheries, Republic of Korea.

MIFAFF, 2010. Classification and Specification of Hazardous Feeds (published in Korean; translated into English). Notification No. 2010-30, Ministry for Food, Agriculture, Forestry and Fisheries, Republic of Korea.

Manzanilla, E. G., Nofrarías, M. Anguita, M., Castillo, M., Perez, J. F., Martín-Orúe, S. M., Kamel, C. and Gasa. J. 2006 Effects of butyrate, avilamycin, and a plant extract combination on the intestinal equilibrium of early-weaned pigs. J. Anim. Sci. 84:2743-2751.

Miles, R. D., Butcher, G. D., Henry, P. R. and Littell, P. R.
2006. Effect of antibiotic growth promoters on broiler performance, intestinal growth parameters and quantitative morphology. Poult. Sci. 85:476-485.

Ohashi, Y and Ushida, K. 2009. Health-beneficial effects of probiotics: its mode of action. Anim. Sci. J. 80:361-371.

Olas, B., Wachowicz, B., Stochmal, A. and Oleszek, W. 2003. Inhibition of oxidative stress in blood platelets by different phenolics from Yucca schidigera Roezl. bark. Nutrition 19:633-640.

Owusu-Asiedu, A., Nyachoti, C. M. and Marquardt, R. R. 2003. Response of early-weaned pigs to an enterotoxigenic Escherichia coli (K88) challenge when fed diets containing spray-dried porcine plasma or pea protein isolate plus egg yolk antibody, zinc oxide, fumaric acid, or antibiotic. J. Anim. Sci. 81:1790-1798.

Phillips, I. 2007. Withdrawal of growth-promoting antibiotics in Europe and its effects in relation to human health. Int. J. Antimicrob. Agents 30:101-107.

Ryniba, I. V., Liu, H., Gor, Y. and Feinmark, S. J. 1997. Regulation of leukotriene A4 hydrolase activity in endothelial cells by phosphorylation. J. Biol. Chem. 272:31865-31871.

Sehm, J., Lindermayer, H., Dummer, C., Treutter, D. and Pfaffl, M. W. 2007. The influence of polyphenol rich apple pomace or red-wine pomace diet on the gut morphology in weaning piglets. J. Anim. Physiol. Anim. Nutr. 91:289-296.

Snary, E. L., Kelly, L. A., Davison, H. C., Teale, C. J. and Wooldridge, M. 2004. Antimicrobial resistance: a microbial risk assessment perspective. J. Antimicrob. Chemother. 53:906917.

Solomon, S. E. and Tullett, S. G. 1988. The effect of virginiamycin on the ileum of the domestic fowl. 1. Light and scanning electron microscope observations. Anim. Tech. 39:157-160.

Stein, H. H. and Kil, Y. 2006. Reduced use of antibiotic growth promoters in diets fed to weanling pigs: dietary tools, part 2 . Anim. Biotechnol. 17:217-231.

Stutz, M. W., Johnson, S. L. and Judith, F. R. 1983. Effects of diet, bacitracin, and body weight restrictions on the intestine of broiler chicks. Poult. Sci. 62:1626-1632.

Thymann, T., Sørensen, K. U., Hedemann, M. S., Elnif, J., Jensen, B. B., Banga-Mboko, H., Leser, T. D. and Sangild, P. T. 2007. Antimicrobial treatment reduces intestinal microflora and improves protein digestive capacity without changes in villous structure in weanling pigs. Br. J. Nutr. 97:1128-1137.

van der Peet-Schwering, C. M., Jansman, A. J., Smidt, H. and Yoon, I. 2007. Effects of yeast culture on performance, gut 
integrity, and blood cell composition of weanling pigs. J. Anim. Sci. 85:3099-3109.

Veselinova, A., Ivanov, N. and Chotinski, D. 1987. Morphological changes in broilers produced by feeding antibiotics. Vet. Med. Nauki. 24:9-14.

Visek W. J. 1978. The mode of growth promotion by antibiotics. J. Anim. Sci. 46:1447-1469.

Wenk, C. 2000. Recent advances in animal feed additives such as metabolic modifiers, antimicrobial agents, probiotics, enzymes and highly available minerals. Review. Asian-Aust. J. Anim. Sci. 13:86-95.

Windisch, W. M., Schedle, K., Plitzner, C. and Kroismayr, A. 2008. Use of phytogenic products as feed additives for swine and poultry. J. Anim. Sci. 86(Suppl.):E140-E148.

Yen, J. T. and Pond, W. G. 1993. Effects of carbadox, copper, or
Yucca shidigera extract on growth performance and visceral weight of young pigs. J. Anim. Sci. 71:2140-2146.

Yin, F., Yin, Y., Kong, X., Liu, Y., He, Q., Li, T., Huang, R., Hou, Y., Shu, X., Tan, L., Chen, L., Gong, J., Kim, S. W. and $\mathrm{Wu}$, G. 2008. Dietary supplementation with Acanthopanax senticosus extract modulates gut microflora in weaned piglets. Asian-Aust. J. Anim. Sci. 21:1330-1338.

Zhao, J., Harper, A. F., Estienne, M. J., Webb, Jr., K. E., McElroy, A. P. and Denbow, D. M. 2007. Growth performance and intestinal morphology responses in early weaned pigs to supplementation of antibiotic-free diets with an organic copper complex and spray-dried plasma protein in sanitary and nonsanitary environments. J. Anim. Sci. 85:1302-1310.

(Received Mar. 28, 2011; Revised Jun. 14, 2011; Accepted Jun. 17, 2011) 